\title{
Laser-based imaging for cocoa pods maturity detection
}

\begin{abstract}
Non-destructive and laser-based technologies have been explored widely in recent years as a way to monitor fresh produce and crops quality in the agriculture sector. In this study, the effectiveness of laser-induced backscattering imaging (LLBI) was investigated to determine the firmness and colour of cocoa pods at different maturity stages. The LLBI system with 1 $\mathrm{mm}$ laser diode beam diameter emitting at $658 \mathrm{~nm}$ and $705 \mathrm{~nm}$ wavelengths were used to capture backscattered images of Theobroma cacao at three different maturity stages, which were unripe, ripe and over-ripe. The samples were also measured using reference measurement such as colorimeter and handheld penetrometer for measuring colour and firmness, respectively, in order to compare with the LLBI. Results indicated that chroma (C) regressed linearly well with the backscattering parameters with a coefficient of determination (R2) of 0.755 for $658 \mathrm{~nm}$ and 0.800 for $705 \mathrm{~nm}$. Classification of samples according to their maturity stages resulted in $90 \%$ correctly classified samples into an unripe group using a laser diode at $658 \mathrm{~nm}$ and $95 \%$ at $705 \mathrm{~nm}$. These findings also revealed that LLBI with laser diode emitted light at $705 \mathrm{~nm}$ wavelength gave better evaluation and classification results compared with $658 \mathrm{~nm}$. This study has demonstrated the ability of non-destructive LLBI technique to evaluate the maturity stages of cocoa pods.
\end{abstract}

Keyword: Laser-based imaging; Backscattering imaging; Fruit maturity; Cocoa; Nondestructive technique 